\title{
Patient Reported Outcome Analysis after Posterior Decompression and Posterolateral Fusion Surgery in Lumbar Degenerative Spondylolisthesis
}

\author{
Prakash Paudel $F C P S^{1}$, Damber Bikram Shah $M S^{2}$, Sumit Joshi $M S^{3}$, Prasanna Karki PhD ${ }^{4}$, Samip Jung Budhathoki \\ $M B B S^{5}$, Gopal Raman Sharma $M S^{6}$
}

1,2,3,4,5,6 Department of Neurosciences, Nepal Mediciti Hospital, Lalitpur, Nepal

Date of submission: $11^{\text {th }}$ July 2020

Date of acceptance: $5^{\text {th }}$ August 2020

Date of publication: $12^{\text {th }}$ August 2020

\begin{abstract}
Introduction: Lumbar degenerative spondylolisthesis is an acquired slippage of a vertebra due to degenerative arthritis of the facet joints without any defect in the vertebral ring. Degenerative spondylolisthesis is commonly treated with posterior decompression and posterolateral fusion. This study aims to evaluate the clinical outcome of posterior decompression and instrumented posterolateral fusion surgery by analysing patient reported outcome measures.
\end{abstract}

Materials and Methods: A retrospective study in which patients who had posterior decompression and instrumented posterolateral fusion for lumbar degenerative spondylolisthesis between September 2017 and August 2019 at Nepal Mediciti Hospital were included in the study. Other types of spondylolisthesis managed with similar technique and patients who had follow up period of less than three months were excluded. Functional outcome was assessed by comparing pre and post-operative patient reported outcome measures: VAS leg pain, VAS back pain and Oswestry Disability Index (ODI). The paired t-test was used for statistical analysis.

Results: Of the 16 patients, $81.25 \%$ were female. Mean age and mean follow up period were $58.81 \pm 10.47$ years and 13.56 \pm 7.15 months respectively. Seventy five percent had grade I spondylolisthesis. Most common level of spondylolisthesis was L4/5 (62.5\%). Fourteen patients reported improvement in their symptoms after surgery.

The changes in functional outcome scores between baseline and at follow up evaluation were as follows: $32.70 \pm$ 17.44 points for ODI, $3 \pm 1.89$ for VAS leg pain, and $5.37 \pm 2.36$ for VAS back pain $(\mathrm{P}<0.001)$. Superficial wound infection was the most common complication observed in $18.3 \%$.

Conclusion: In our case series, $87.5 \%$ had improvement in their symptoms after surgery. The change in mean score of patients' reported outcome measures before and after surgery was statistically significant. We recommend a prospective comparative study between decompression alone and the fusion technique for the evaluation of long term functional outcome.

Key words: Degenerative Spondylolisthesis, Lumbar, Instrumented Posterolateral Fusion, Outcome

\section{Introduction}

Access this article online
Website: https://www.nepjol.info/index.php/NJN
DOI: https://doi.org/10.3126/njn.v17i2.30498
HOW TO CITE
Paudel P, Shah DB, Karki P, Budhathoki SJ, Sharma GR. Patient
Reported Outcome Analysis after Posterior Decompression
and Posterolateral Fusion Surgery in Lumbar Degenerative
Spondylolisthesis. NJNS. 2020;17(2):35-41

'ORCID id: 0000-0002-8830-3908

${ }^{2}$ ORCID id: 0000-0002-5707-7696

${ }^{3}$ ORCID id: 0000-0002-7883-9354

${ }^{4}$ ORCID id: 0000-0003-1469-3517

${ }^{5}$ ORCID id: 0000-0001-6925-4314

${ }^{6}$ ORCID id: 0000-0003-3638-4993
$\mathrm{D}$ egenerative spine disease (DSD) is one of most common spine pathology affecting up to $80 \%$ of the population at some point in their life. The annual

\author{
Address for correspondence: \\ Dr. Prakash Paudel, \\ Associate Consultant Neurosurgeon \\ Department of Neurosciences, \\ Nepal Mediciti Hospital, Sainbu, Lalitpur, Nepal \\ PO Box 44600 \\ Contact number: +9779841400194 \\ E-mail: docppaudel@gmail.com \\ Copyright (C) 2020 Nepalese Society of Neurosurgeons (NESON) \\ ISSN: 1813-1948 (Print), 1813-1956 (Online)
}

(i) (8) This work is licensed under a Creative Commons Attribution-Non Commercial 4.0 International License. 


\section{Paudel et al}

prevalence of DSD is $15 \%$ to $40 \%$ leading to disability in $1 \%$ to $2 \%$ of the population. ${ }^{1}$ Spinal stenosis and spondylolisthesis, the sequelae of degeneration, together affect up to $20 \%$ of the U.S. population. ${ }^{2}$

Newman and Stone coined the term degenerative spondylolisthesis (DS) in 1955, who defined it as an acquired slippage of the vertebra secondary to degenerative arthritis of facet joints without defect in pars interarticularis. ${ }^{3}$ Karkaldy Willis described the degenerative cascade in 1970s. ${ }^{4}$ The cascade begins with disc degeneration, progresses to destabilization and finally leads to re-stabilization. The cause of pain in DS has been described as multi-factorial: purely mechanical pain due to degenerative changes or neurogenic claudication from spinal stenosis or radicular pain due to nerve root impingement in the lateral recess or neural foramen. ${ }^{5}$ In this spectrum of cascade, surgery is indicated for instability, progressive neurological deficit or those not responding to medical management.

Although various surgical techniques have been used for the management of DS, the superiority of one over other was not well evident in the literature. ${ }^{6,7}$ In general, outcomes were commonly assessed based on surgeons' perspective relying on technical success like adequate decompression and/or fusion. Interestingly, surgeons' perspectives and results of imaging exams frequently do not found to be correlated with patient satisfaction., ${ }^{9,10}$ In this context, considering the importance of patient's opinion of results and their satisfaction, we designed a study to evaluate the outcome of posterior decompression and instrumented posterolateral fusion (PLF) surgery in patients with lumbar DS using patient reported outcome instruments- visual analogue scale (VAS) leg pain, VAS back pain and Oswestry Disability Index (ODI).

\section{Materials and Methods}

\section{Study Design and Patient Population}

We designed a retrospective study. Ethical approval was taken from Institutional Review Committee of the hospital. A consecutive cohort of patients who had posterior decompression and instrumented posterolateral fusion (PLF) surgery for lumbar degenerative spondylolisthesis between September 2017 and August 2019 at Nepal Mediciti Hospital was identified from medical record files. Patients whose data were incomplete, who had follow up period of less than three months and all other types of spondylolisthesis were excluded. Demographic, clinical, radiographic reports and operative records were reviewed. Patients were evaluated with respect to their age, sex, duration of symptoms, clinical presentation, level and grade of spondylolisthesis. Grading of spondylolisthesis was classified from grade I to $\mathrm{V}$ according to Meyerding classification system. Any intra-operative and/or postoperative complication was documented.

\section{Pre-operative management and surgical indication}

All patients were managed with conservative treatment with adequate analgesics and physical therapy for at least 12 weeks. Indication for grade I degenerative spondylolisthesis was failure of conservative management and unstable spondyolisthesis (translation in spondylolisthesis in standing lateral flexion/extension $\mathrm{x}$ ray of lumbosacral spine) while the indication for surgery in grade II spondylolisthesis was failure of conservative treatment with progressive neurological deficit.

\section{Surgical technique}

Surgical procedure was performed through an open midline longitudinal approach in prone position. Pedicle screws were placed based on anatomic landmarks and fluoroscopic image assistance. The neural element decompression was performed by a midline laminectomy, medial facetectomy and foraminotomy. Posterolateral fusion was facilitated by inter-transverse grafting along the decorticated surface of the transverse process using autologous local bone graft collected during laminectomy. Post-operative antero- posterior and lateral $\mathrm{X}$ ray of lumbosacral region was done to confirm the position of implants and alignment of bony elements.

\section{Study Measures/Statistics}

Outcome data included visual analogue pain scale (VAS) and Oswestry Disability Index (ODI). Patients were consented and asked to complete a survey before surgery and at the time of follow up at least three months after surgery in out-patient department. Outcome was assessed by comparing pre and post-operative patient-reported outcome measures: visual analogue scale (VAS) leg pain, visual analogue scale (VAS) back pain and Oswestry disability index (ODI). The paired t-test was used for statistical analysis. SPSS 17 (IBM, Chicago, IL, USA) was used for data analysis. P value $<0.05$ was considered significant.

\section{Results}

Of 19 patients with degenerative lumbar spondylolisthesis were operated in 24 months, 16 were included in the study. Patient demographics and clinical characteristics are summarized in Table 1.

Majority of the patients were female $(81.25 \%)$, with female to male ratio of $4.3: 1$. Mean age was 58.81 years (SD 10.47, range 45-80). The mean and the 
minimum duration of follow up were 13.5 and 5 months respectively. $75 \%$ had grade I spondylolisthesis while grade II spondylolisthesis was seen in $25 \%$. Most of the deformity was seen at L4/5 Level followed by L5/S1 level $(62.5 \%$ vs $38.5 \%)$.

$87.5 \%$ improved after surgery. The changes in functional outcome scores between baseline and at postoperative follow up evaluation were as follows: 32.70 \pm 17.44 points for ODI, $3 \pm 1.89$ for VAS leg pain, and 5.37 \pm 2.36 for VAS back pain. Mean scores of VAS leg pain,
VAS back pain and ODI before surgery and during follow up were presented in Table 2.

Most common perioperative complication in our series was wound dehiscence seen in $18.75 \%$ followed by intra-operative cerebrospinal fluid (CSF) leak (6.5\%). All the patients who had wound dehiscence in our series $(n=3)$ were elderly diabetic (age $>65$ years). One of them was suffering from Cushing disease who underwent two level fixation and fusion because of risk of hypercortisolemiainduced osteoporosis. (See Figure 1 and 2)
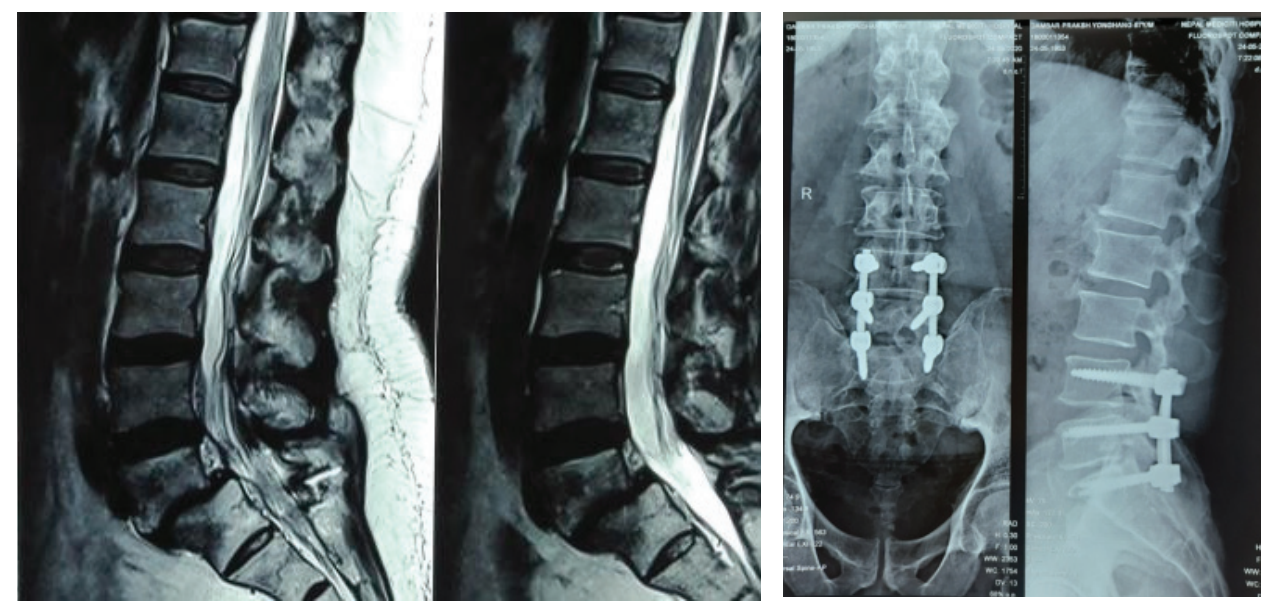

Figure 1: (A) MRI image of lumbosacral Spine of 45-year female with Cushing disease showing grade II degenerative spondylolisthesis at L5/S1 level, (B)Post operative X ray images showing reduction with instrumented posterolateral fixation and fusion.
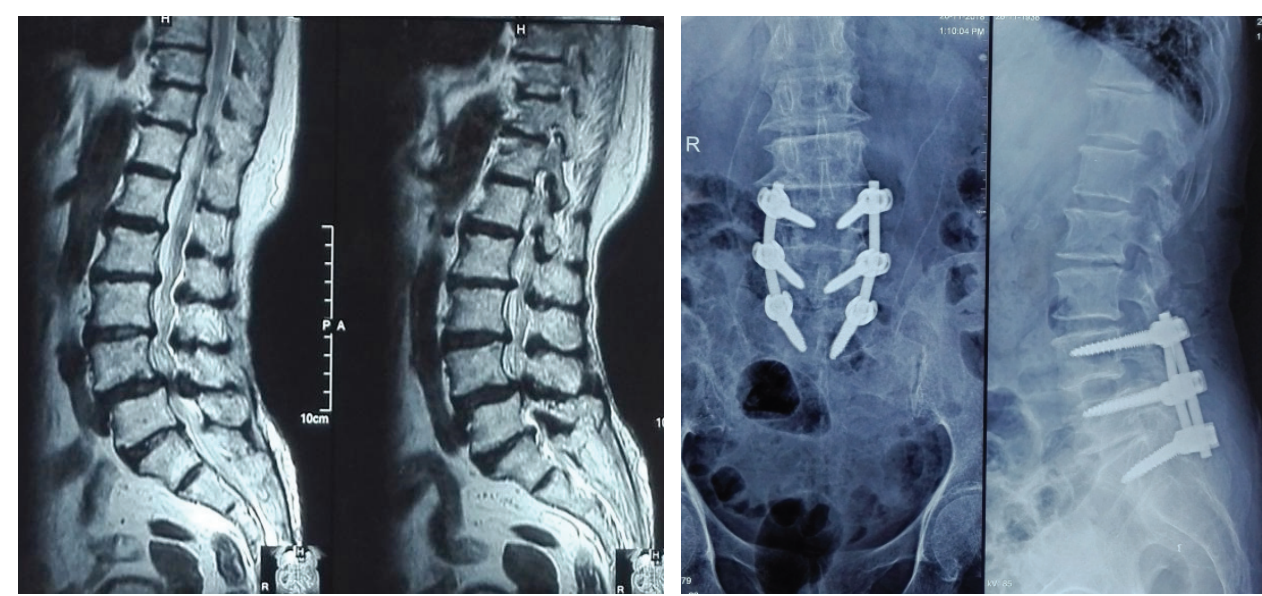

Figure 2: (A) MRI Lumbosacral Spine of 80-year female showing grade I degenerative spondylolisthesis at L4/5 level, (B) Post-operative $X$ ray images showing reduction with instrumented posterolateral fixation and fusion. We included L5/S1 in this case due to old age and osteopenic bone to avoid junctional failure. 


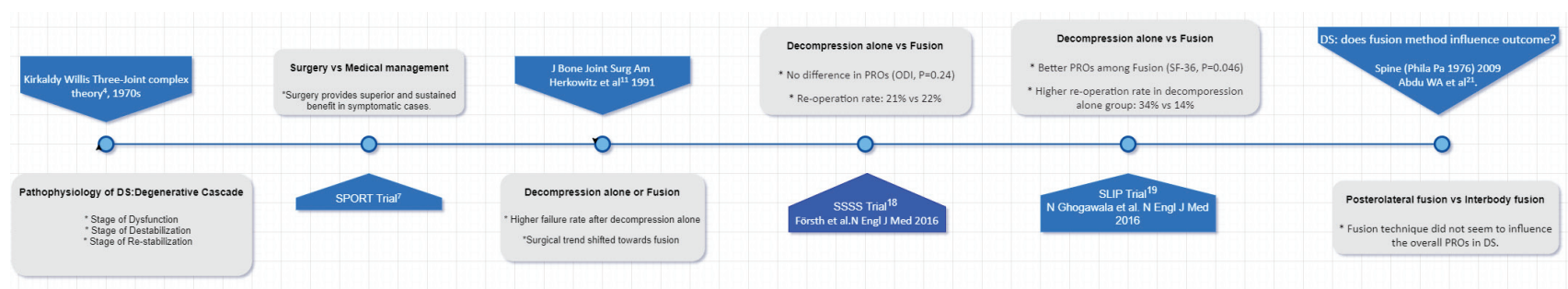

Figure 3: Evolution of Treatment paradigm in Degenerative Spondylolisthesis

\begin{tabular}{l|cc}
\hline Age $($ mean $\pm \mathrm{SD})(\mathrm{y} *)$ & & $58.8 \pm 10.5$ \\
\hline Sex $[\mathrm{n}(\%)]$ & Female & $13(81.25)$ \\
\hline Clinical symptomatology & Male & $3(18.75)$ \\
\hline Comorbidity & Back pain with claudication & $11(68.75)$ \\
& Back pain with radiculopathy & $5(31.25)$ \\
\hline & DM & $3(18.75)$ \\
\hline DOI (Mean \pm SD) $\left(m^{* *}\right)$ & Bed ridden & $2(12.5)$ \\
\hline Meyerding grading & Sphincter dysfunction & $1(6.5)$ \\
\hline Level of spondylolisthesis $[\mathrm{n}(\%)]$ & Cushing disease & $1(6.25)$ \\
\hline FU (Mean \pm SD) (m**) & L4/5 & $22.06 \pm 19.08$ \\
\hline Intraoperative complications $[\mathrm{n}(\%)]$ & Dural tear & $12(75)$ \\
\hline Postoperative complications $[\mathrm{n}(\%)]$ & Wound dehiscence, (Superficial) & $4(25)$ \\
\hline Mortality & Grade I & $10(62.5)$ \\
\hline y: year,** m: month & & $6(37.5)$ \\
\hline
\end{tabular}

Table 1: Patient Baseline Demographic and Clinical Characteristics, $N=16$

\begin{tabular}{l|c|c|c|c}
\hline \multicolumn{1}{c|}{ Variables } & Pre-operative & Post-operative & Mean difference (95\% CI) & P Value \\
\hline VAS leg pain $($ mean \pm SD) & $6.81 \pm 1.56$ & $3.81 \pm 1.22$ & $3.0 \pm 1.89(1.98-4.01)$ & $<0.001$ \\
\hline VAS back pain $($ mean \pm SD) & $8 \pm 1.03$ & $2.63 \pm 1.85$ & $5.37 \pm 2.36(4.11-6.63)$ & $<0.001$ \\
\hline ODI (mean \pm SD) & $56.66 \pm 10.33$ & $23.96 \pm 12.40$ & $32.70 \pm 17.44(23.41-42)$ & $<0.001$ \\
\hline
\end{tabular}

Table 2: Comparison of Mean Change in Outcomes before and after PLF (Posterolateral fusion)

\section{Discussion}

Previous studies have shown that degenerative spondylolisthesis is commonly seen in elderly female (above 50 years) with a female-to-male ratio of $6: 1$, with L4/5 being the most common level of deformity. ${ }^{11,12}$ This was consistent with our findings.
Meyerding classification is widely used to classify DS. Low grade spondylolisthesis is the commonest deformity associated with degeneration. As consistent with previous studies, ${ }^{13}$ all of our patients had low grade spondylolisthesis (grade I and II) with grade I being the most common entity (75\%).

In general, a minimum of 2-year follow-up is suggested for patient-reported outcomes (PROs) to 
adequately assess the therapeutic effect of surgery in spine and musculoskeletal clinical research. Ayling et al investigated on the appropriate follow up time for clinical outcome research in spine surgery and found that the time to plateaued recovery after surgery for VAS back and leg pain was 3 months; and 12 months for disability indices (ODI) for patients with degenerative spondylolisthesis who were treated with fusion. ${ }^{14}$ In our study the minimum and the mean duration of follow up were 5 and 13.5 months respectively.

In our study, all patients were managed with PLF. Fourteen out of sixteen patients improved after surgery. There was significant change in the means of VAS leg pain, back pain and ODI scores from $6.8,8$, and 56.66 before surgery to $3.8,2.6$ and 23.96 respectively after surgery $(\mathrm{p}<0.001)$. Omidi-Kashani $\mathrm{F}$ et $\mathrm{al}^{15}$ published a similar study in which pre-operative pain and disability (VAS and ODI) improved from 8.8 and 71.6 to postoperative 2.1 and 28.7 respectively after PLF surgery lumbar DS $(\mathrm{p}=001)$. Urquhart et $\mathrm{al}^{16}$ did a retrospective study and found that the change in mean of leg pain, back pain and ODI scores after PLF for lumbar DS were -5.9, -4.1 and -26 respectively, which was similar to our findings in which the change in the means were $-3,-5.37$ and -32.7 respectively. Similarly, Gottschalk et al found a significant change in visual analogue pain scale (-3.45) and ODI (-17.79) during average follow-up of 38.7 months after PLF surgery for DS.${ }^{17}$ Likewise the changes in VAS back pain and VAS leg pain and ODI scores after fusion surgery for DS in Swedish Spinal Stenosis Study (SSSS) trial were $2.8,3.2$ and 16 respectively. ${ }^{18}$ The difference in pre and post-operative ODI score at 2 years after PLF surgery was -26.3 in SLIP (Spinal Laminectomy versus Instrumented Pedicle Screw) trial. ${ }^{19}$

To consider the given treatment as effective, the minimum difference in outcome score should at least correspond to minimum clinically important difference (MCID) value. The minimum difference in score in our study were 15.26 for ODI, 1.11 for leg pain, and 3.01 back pain which correspond to the MCID reported in literature. The reported MCID value for grade I degenerative lumbar spondylolisthesis, were 14.3 points for ODI, 1.7 points for leg pain and 1.6 points for. ${ }^{20}$

Although fusion was associated with better functional outcome, fusion techniques did not seem to influence the overall PROs in DS. ${ }^{11,21}$ Urquhart et $\mathrm{al}^{16}$ and Gottschalk et $\mathrm{al}^{17}$ found no significant difference in the means of outcome measures after PLIF or interbody fusion. Recently, two randomized trials published a high level of evidence for (SLIP trial) ${ }^{19}$ and against (SSSS trial) ${ }^{18}$ the fusion surgery in DS. SSSS trial published a level I evidence against fusion surgery. In contrary, SLIP trial published a level I evidence for fusion surgery in stable grade I DS in the same issue of the same journal: fusion group had significant improvement in PROs while 34\% had to undergo re-surgery for progressive slippage of spondylolisthesis after laminectomy alone in patients with stable grade I DS. Hence fusion or no fusion and the technique of fusion are the topics of ongoing discussion and the treating surgeon has to tailored the approach based on clinical scenario, available evidences and the patient's decision. In our case series, we performed fusion surgery in grade I DS because of translation seen in standing dynamic X ray of lumbosacral spine while in cases of grade II DS fusion was recommended due to high risk of progression of spondylolisthesis with laminectomy alone. The evolution and controversy in the management of lumbar degenerative spondylolisthesis was summarized in figure 3.

Our perioperative complications were higher than that of the findings (wound dehiscence- $6.9 \%$ and CSF leak-4.6\%) reported by Urquhart et al. ${ }^{16}$ Post-operative wound infection and dural tear were seen in $10 \%$ and $11 \%$ respectively in SSSS trial. ${ }^{18}$

\section{Limitation}

This study was limited by small sample size and its retrospective nature. We were not able to assess the evidence of radiological fusion post-operatively. Though smaller in size, this study is trying to incorporate patient's perspective regarding outcome of surgical intervention after spinal surgery in Nepal. Patient' satisfaction and cost effectiveness are important considerations while selecting the surgical technique especially in the context of developing country like Nepal where affordability is a major concern.

\section{Conclusion}

In our case series, $87.5 \%$ had improvement in their symptoms after surgery. The change in mean score of patients' reported outcome measures before and after surgery was statistically significant $(\mathrm{P}<0.001)$. Based on patient reported outcomes, PLF seems to be a viable treatment option in degenerative spondylolisthesis. We recommend a prospective comparative study between decompression alone and the fusion technique to assess the long-term functional outcome.

Conflict of Interest: None

Source(s) of support: None 


\section{References}

1. Friedly J, Standaert C, Chan L. Epidemiology of spine care: the back pain dilemma. Phys Med Rehabil Clin N Am. 2010;21(4):659-77. https://doi.org/10.1016/j. pmr.2010.08.002

2. Ravindra VM, Senglaub SS, Abbas R, et al. Degenerative lumbar spine disease: estimating global incidence and worldwide volume. Glob Spine J. 2018;8(8):784-94. https://doi. org/10.1177/2192568218770769

3. Newman PH, Stone KH. The etiology of spondylolisthesis. J Bone Joint Surg Br. 1963; 45B(1): 39-59. https://doi.org/10.1302/0301$620 \mathrm{X} .45 \mathrm{~B} 1.39$

4. Kirkaldy-Willis WH, Paine KW, Cauchoix J, McIvor G. Lumbar spinal stenosis. Clin Orthop Relat Res. 1974; 99:30-50. PMID: 4274946

5. Sengupta Dilip K, Herkowitz Harry N. Degenerative spondylolisthesis: review of current trends and controversies. Spine (Phila Pa 1976). 2005;30(6): S71-81. https://doi.org/10.1097/01. brs. $0000155579.88537 .8 \mathrm{e}$.

6. Kalichman L, Hunter DJ. Diagnosis and conservative management of degenerative lumbar spondylolisthesis. Eur Spine J. 2008; 17:327-35. https://doi.org/10.1007/s00586-007-0543-3

7. William A. Abdu, Olivia A. Sacks, Anna N.A. Tosteson, Wenyan Zhao, Tor D. Tosteson et al. Long-Term Results of Surgery Compared With nonoperative Treatment for Lumbar Degenerative Spondylolisthesis in the Spine Patient Outcomes Research Trial (SPORT). Spine(Phila Pa 1976). 2018;43(23):1619-30. https://doi.org/10.1097/ BRS.0000000000002682

8. Watters $\mathrm{WC}, 3^{\text {rd }}$, Bono CM, Gilbert TJ, Kreiner DS, Mazanec DJ, Shaffer WO et al. An evidencebased clinical guideline for the diagnosis and treatment of degenerative lumbar spondylolisthesis. Spine J. 2009; 9:609-14. https://doi.org/10.1016/j. spinee.2009.03.016

9. Djurasovic, Mladen, Glassman, Steven, Dimar, John, et al. Does Fusion Status Correlate with Patient Outcomes in Lumbar Spinal Fusion? Spine 2011;36(5):404-409. https://doi.org/10.1097/ BRS.0b013e3181fde2c4.

10. Haefeli M, Elfering A, Aebi M, Freeman BJ, Fritzell $P$, Guimaraes Consciencia $J$ et al. What comprises a good outcome in spinal surgery? A preliminary survey among spine surgeons of the SSE and European spine patients. Eur Spine J. 2008;17(1):104-116. https:// doi.org/10.1007/s00586-007-0541-5
11. Herkowitz HN, Kurz LT. Degenerative lumbar spondylolisthesis with spinal stenosis. A prospective study comparing decompression with decompression and intertransverse process arthrodesis. J Bone Joint Surg Am. 1991;73(6):802-8. PMID: 2071615

12. Jacobsen S, Sonne-Holm S, Rovsing H, Monrad $\mathrm{H}$, Gebuhr P. Degenerative lumbar spondylolisthesis: an epidemiological perspective: the Copenhagen Osteoarthritis Study. Spine (Phila Pa 1976). 2007;32(1):120-5. https://doi.org/10.1097/01. brs.0000250979.12398.96

13. de Schepper EI, Koes BW, Veldhuizen EF, Oei EH, Bierma-Zeinstra SM, Luijsterburg PA. Prevalence of spinal pathology in patients presenting for lumbar MRI as referred from general practice. Fam Pract. 2016;33(1):51-6. PMID: 26659653

14. Ayling OGS, Ailon T, McIntosh G, Soroceanu A, Hall $\mathrm{H}$, Nataraj A, et al. Clinical outcomes research in spine surgery: what are appropriate follow-up times? J Neurosurg Spine. 2018;30(3):397-404. https://doi. org/10.3171/2018.8.SPINE18715

15. Omidi-Kashani F, Hassankhani EG, Shiravani R, Mirkazemi M. Surgical Outcome of Reduction and Instrumented Fusion in Lumbar Degenerative Spondylolisthesi. Iran J Med Sci. 2016;41(1):13-18. PMID: 26722140

16. Urquhart JC, Alnaghmoosh N2, Gurr KR, Bailey SI, Tallon C, Dehens S, et al. Posterolateral versus Posterior Interbody Fusion in Lumbar Degenerative Spondylolisthesis.Clin SpineSurg. 2018;31(9):E44652. https://doi.org/10.1097/BSD.0000000000000698

17. Gottschalk MB, Premkumar A, Sweeney K, Boden SD, Heller J, Yoon ST, et al. Posteriolateral Lumbar Arthordesis with and without Interbody Arthrodesis for L4-L5 Degenerative Spondylolisthesis: A Comparative Value Analysis. Spine (Phila Pa 1976). 2015;40(12):917-25. https://doi.org/10.1097/ BRS.0000000000000856

18. Försth P, Ólafsson G, Carlsson T, Frost A, Borgström F, Fritzell P, et al. A Randomized, Controlled Trial of Fusion Surgery for Lumbar Spinal Stenosis. N Engl J Med. 2016;374(15):1413-23. https://doi. org/10.1056/NEJMoa1513721

19. Ghogawala Z, Dziura J, Butler WE, Dai F, Terrin N, Magge SN, et al. Laminectomy plus Fusion versus Laminectomy Alone for Lumbar Spondylolisthesis. N Engl J Med. 2016;374(15):1424-34. https://doi. org/10.1056/NEJMoa1508788

20. Asher AL, Kerezoudis P, Mummaneni PV, Bisson EF, Glassman SD, Foley KT et al. Defining the minimum clinically important difference for grade I 
Patient reported outcome after posterolateral spinal fusion surgery

degenerative lumbar spondylolisthesis: insights from the Quality Outcomes Database. Neurosurg Focus. 2018;44(1):E2. https://doi.org/10.3171/2017.10. FOCUS17554
21. Abdu WA, Lurie JD, Spratt KF, Tosteson AN, Zhao W, Tosteson TD, et al. Degenerative spondylolisthesis: does fusion method influence outcome? Four year results of the Spine Patient Outcomes Research Trial. Spine (Phila Pa 1976). 2009; 34:2351-60. https:// doi.org/10.1097/BRS.0b013e3181b8a829 